\title{
Linguistic Skills and Working Memory in Monolingual and Bilingual Children Born Prematurely: Preliminary Data
}

\author{
Roxanne Mariette Belanger*, Chantal Mayer-Crittenden, Michelle Brouillette \\ Laurentian University, Sudbury, Canada
}

\begin{abstract}
Determining the effects of prematurity on language development is a complex phenomenon. This is especially true when one considers that many children live in multilingual and multicultural environments. When preparing for an evaluation, speech-language pathologists must use assessment tools that allow them to objectively determine the communication abilities of their client; the selection of assessment tools is a critical step in this evaluation process. However, in Official Minority Language Communities (OMLC), this process is made more difficult by the lack of standardized assessment tools and regional norms.
\end{abstract}

At present, no study has examined the linguistic competencies of bilingual children born prematurely and taken into consideration the implication of residing in a minority language community. Using a formal evaluation battery comprised of French and English language tests, this study examined the linguistic knowledge, linguistic processing and working memory of three groups of premature children having average non-verbal language skills: monolingual children speaking English (ENG) $(n=5, X=6.6$ years; $S D=1.1)$, bilingual children whose dominant language was French ( $F D)(n=5, X=9.3$ years; $S D=0.99)$, and bilingual children whose dominant language was English (ED) $(n=3, X=8.1$ years; $S D=1.5)$.

Results showed that regardless of language dominance, birth weight and degree of prematurity, participants' scores fell within the average range on simple language tasks, or tasks measuring linguistic knowledge. However, most children experienced difficulties with complex language tasks measuring linguistic processing, as well as working memory. More bilinguals then monolinguals were identified as having a PLI. Also, of those identified, only one participant was identified as having language delays in the preschool period, demonstrating that the difficulties observed in this study developed at a later stage. Long-term follow-up is necessary in order to determine if these weaknesses are maintained, or if they impact academic success.

Keywords: Prematurity, Francophones, Linguistic Development, Linguistic knowledge, Linguistic processing, Simple language skills, Complex language skills, Minority language

\section{INTRODUCTION}

Approximately 350,000 babies are born in Canada each year [1]. Preterm birth has been the leading cause of infant mortality in developed countries for the past decade [2]. In Canada, it is the number one cause of infant mortality, leading to about one third of all infant deaths [3].

From a historical standpoint, few premature infants have been thoroughly moni-

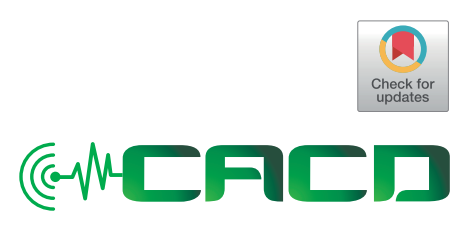

Received: November 11, 2016

Revision: February 9, 2017

Accepted: September 5, 2017

Correspondence:

Roxanne Belanger

Assistant Professor, Laurentian University 935 Ramsey Lake Rd, Sudbury, Ontario, Canada

Tel: (705) 675-1151 x 4306

Fax: (705) 671-3889

E-mail: rbelanger@laurentian.ca

(C) 2017 The Korean Association of SpeechLanguage Pathologists

This is an Open Access article distributed under the terms of the Creative Commons Attribution Non-Commercial License (http:// creativecommons.org/licenses/by-nc/4.0/) which permits unrestricted non-commercial use, distribution, and reproduction in any medium, provided the original work is properly cited. 
tored on a long-term basis [4]. More recently, the importance of surveillance has been highlighted [4]. Initially, the main focus was on the identification of major neurodevelopmental morbidities in infants born at extremely low birth weight (ELBW) or extremely low gestational age [5]. However, more recently, a higher prevalence of minor morbidities is being reported in premature children [6]. These minor morbidities often present later in childhood and though not disabling in the traditional sense, act synergistically to create significant functional challenges in the school and social settings [5]. Also, there is increasing literature that similar, albeit milder issues exist children born moderately or late preterm [7]. This is especially important information given than these infants account for the majority of preterm births [8]. More information is needed regarding the linguistic development of premature children in general and, more specifically, in moderately or late preterm children as they have been considered until recently at low risk for impairment.

\section{Prematurity: a definition}

A term baby is born between 37 to 42 weeks of gestation; a baby born before 37 weeks' gestation is therefore considered to be premature [3]. At birth, premature infants are often classified according to risk factors affecting survival rate, health and development. Gestational age (GA) is one of these factors and can be subdivided into three subcategories: late preterm, born between 34-36 weeks of gestation; very preterm, born between 29 to 33 weeks of gestation, and extremely preterm, born at 28 weeks of gestation or less [9].

Birth weight is another important factor for classification [3]. A child with a normal birth weight is born weighing between 2,500 and 3,999 grams. A child is labelled as having low birth weight (LBW) when weighing between 1,500-2,500 grams; very low weight (VLBW) when weighing less than 1,500 grams and an extremely low birth weight (ELBW) when weighing less than 1000 grams at birth [10].

Low birth weight and low gestational age have been shown to be good predictors of deficits or impairments; more specifically, the probability of impaired development has been shown to be inversely proportional to birth weight or gestational age $[11,12]$. Similarly, cognitive impairments have been shown to be strongly correlated to gestational age or birth weight [13].

\section{Language skills in premature infants}

Although a reasonable body of work has reported on the lin- guistic development of preterm children and demonstrated that communication and language are the more commonly affected domains, the exact nature and developmental sequence of these delays is less well understood [14]. During the preschool period, some authors have demonstrated that, compared to peers born at term, vocabulary and receptive language functions are within the normal range, but mean length of utterance (MLU) and more complex language skills, such as abstract verbal reasoning and understanding of syntax, are affected [15].

In a systematic review investigating the developmental course of language functions in preterm-born children (GA < 37 weeks), van Noort-van der Spek, Franken \& Weisglas-Kuperus (2012) compared performance of preterm children to those born term throughout childhood by performing a metaanalysis. [16] In this study, language functions were divided into simple and complex, to distinguish between more basic and complex verbal processes. Simple language function included measures of vocabulary and the acquisition of short main clauses. Complex language functions were characterized by the integration across multiple language components and comprised the meaning of complex concepts, including verbs or relational terms, as well as sentences consisting of main and subordinate clauses [16]. Results demonstrated that children born preterm scored lower compared to children born term on simple and complex language function tests, even in the absence of major disabilities and independent of socio-economic status. For complex language functions, group differences between preterm- and term-born children increased significantly from 3 to 12 years of age [16].

The prevalence of Specific Language Impairment (SLI) in children born prematurely is less well understood. For example, in a sample of 3.5 year-old children born very preterm (mean GA 30 weeks), about one-third were characterized as language impaired (LI) [17]. Similarly, in the Scottish Low Birth Weight study, 4-year-old children born at less that 30 weeks' gestation and of low birth weight (LBW) were found to score more poorly than their peers on the Bus Story, a measure found to be predictive of SLI [18]. The authors replicated this study in preterm children between three and four years of age and found that the preterm group performed more poorly on short-term memory and language measures, determining that approximately one-third of these children were at risk for persisting language difficulties [19].

Conversely, Kern and Gayraud (2007), studying lexical and grammatical development in a group of 24-month old Fran- 
cophone infants born extremely, very and moderately premature, demonstrated that moderately premature infants did not differ significantly from term infants [12]. However, children born extremely and very premature repeatedly had scores that were significantly lower than those of their peers born at term. Since the premature participants had results that resembled those of their younger peers, the authors concluded that the observed differences constituted a language delay, rather than SLI [12]. Comparably, Wolke, Samara, Bracewell \& Marlow (2007), in the EPICure study, completed formal cognitive, language, phonetic and speech assessments of 6-year children born extremely prematurely and compared them to a control group of children born at term [20-22]. The children born preterm had an increased risk of language problems and overall school difficulties, however differences in general cognitive scores explained the specific language and phonetic awareness deficits [22].

Given the variety of variables involved in language development and the range of language trajectories observed in different groups of premature children, a consensus regarding linguistic development has not yet been reached. Future research with longitudinal designs has been recommended by many authors in order to determine the causal directions underlying the developmental course.

\section{Bilingualism and linguistic status}

The proper identification of linguistic delays is made even more complex when one considers children living in a multilingual environment. In particular, three characteristics of bilingual children make it difficult to accurately identify delays: an uneven distribution of abilities in the child's two languages, cross-linguistic association within bilingual learners, and individual variation due to social circumstances [23]. It has been reported that bilingual children deserve more attention in terms of the detection of speech and language delays because of both the lack of screening instruments for this population and because of the large diversity of this group [24].

Bilingual children can learn two languages simultaneously or sequentially [25]. Simultaneous bilingualism occurs when the child is exposed to two languages before the age of three. These children become competent speakers in both languages if there is a continuous input and opportunity to use both linguistic systems [26]. Sequential bilingualism is observed in children who are exposed to one language (L1) at birth and learn a second language (L2) after the age of three [25]. Generally, bilingual children are not considered to have limited linguistic experience, but their vocabulary in each language can be affected by bilingual language learning [27]. However, factors such as age, level of input, motivation, personality and typology between languages can influence this trajectory [28]. Overall, even if the development of lexical and morphosyntactic knowledge initially appears late in bilinguals when compared to monolinguals, bilingual language learners follow most of the same language milestones [25,29-31].

With regards to social status and personal identity, the acquisition of a new language and the loss of a minority language have become important phenomena in Canada [32]. In Ontario, Canada, Francophones live in a minority context in most of the province [33]. In many communities, the contact between languages impacts many individuals. According to some authors, children are constantly exposed to English and it has a significant influence on French, especially in children [34]. Moreover, in these communities, many English-speaking children learn French, the minority language, in French schools $[35,36]$. This minority language context makes the acquisition of French (L2) quite difficult because there are very few opportunities to communicate in that language outside of school $[37,38]$. Often, schools are the only place where children can practice speaking French $[39,40]$.

In the field of speech language pathology, it is important to understand the influence of linguistic context on the acquisition of language skills [35]. Speech-language assessment must take linguistic differences into consideration. Otherwise, an incorrect label or diagnosis of language disorder can be given when, in fact, differences could be due to the regional linguistic context [35].

Presently, only one other study has examined the linguistic development of premature unilingual and bilingual children born in an Official Minority Linguistic Community (OMLC). AUTHOR (2013) demonstrated that, at approximately 2 years of age, $45 \%$ of the participants were identified as having an expressive language delay and $58 \%$ as having a receptive language delay. Interestingly, the largest proportion of children with delays were born moderately preterm, followed closely by those born extremely preterm [41]. Finally, the results also demonstrated that children whose parents had low socioeconomic status (SES) were particularly vulnerable.

\section{METHODS}

This study examines the linguistic knowledge, linguistic processing and working memory of three groups of premature 
children: French-English bilinguals (dominant language is French), English-French bilinguals (dominant language is English), and monolingual Anglophones. This study received ethical approval from the Research Ethics Board at Laurentian University and Health Sciences North.

\section{Participants}

Participants ( $\mathrm{n}=82$ ) from a previous study (AUTHOR, 2013) were contacted by telephone during the recruitment process. Of these participants, 11 families agreed to participate in the study, two of which had twins. Consequently, the total sample was 13 children [31].

Participants were divided according to the level of exposure to French and English, as reported by parents, as well as the language of communication with peers and family members. Three groups were created: monolingual children speaking English $(E N G)(n=5, X=6.6$ years; $S D=1.1)$, bilingual children whose dominant language was French (FD) ( $n=5, X=9.3$ years; $\mathrm{SD}=0.99$ ) and bilingual children whose dominant language was English $(\mathrm{ED})(\mathrm{n}=3, \mathrm{X}=8.1$ years; $\mathrm{SD}=1.5)$. Overall, the FD children had obtained less input in English than all other groups, but more input in French then the ED children. The ENG children had received very little input (less than 5 hours per week) in French (see AUTHOR, 2014, for more details on linguistic status) [25]. The characteristics of these children can be found in Table 1 .

\section{Procedure}

The Brief IQ subtests of the Leiter International Performance Scale-Revised were used to measure nonverbal intelligence [42]. The cut-off score for inclusion in the present study was 85. Hearing was not formally tested, but caregivers, teachers and participants reported no concerns with hearing at the time of the assessment.

The formal evaluation comprised of a battery of French and English language tests. Using Bialystok and Ryan's (1985) definition of linguistic knowledge and cognitive control, the tests were divided according to the skills measured in each language: linguistic knowledge, linguistic processing or working memory [43]. The various tests used and the categories they fall under are listed below.

Linguistic knowledge refers to contextual tasks, where participants' ability to comprehend the task depend on access to meaning and structure, thus increasing the need for cognitive control [43]. In this study, the term linguistic knowledge as opposed to cognitive control was used, however, the significance is the same. For example, during a receptive vocabulary task, participants were asked to identify one object from a group of four. In order to correctly identify the object, linguistic knowledge or meaning for all items is required. Conversely, linguistic processing refers to tasks requiring attention to form, as opposed to meaning, and is linked to executive functioning [43]. For example, when asked to follow a direction, participants must first understand the meaning of the words being used and the structure of the linguistic message, then focus on the form and pay close attention to the details.

Finally, working memory is responsible for the treatment and temporary classification of information, but is limited it its storage capacity [44]. Studies consistently show that children with SLI have associated deficits in memory and other cognitive abilities [45-47]. Using Baddeley's model of working memory, the relationship between verbal working memory (VWM) and phonological short-term memory (PSTM) and language impairment has been examined using tasks measuring these skills. To measure PSTM, a non-word repetition (NWR) task is often used. Children with SLI have been found to have poorer NWR skills compared with age- and languagematched controls [48-51]. NWR tasks have also been found to be relatively uninfluenced by social and cultural backgrounds, unlike measures of learned knowledge [52-54]. In tasks involving verbal working memory, results on this task was a significant predictor of variance in both later receptive and ex-

Table 1. Characteristics and numbers of participants in the study

\begin{tabular}{|c|c|c|c|c|}
\hline Participants & $\begin{array}{c}28 \text { weeks } \\
\text { or less } \\
(n=2)\end{array}$ & $\begin{array}{l}\text { 29-34 weeks } \\
\quad(n=10)\end{array}$ & $\begin{array}{l}\text { 35-37 weeks } \\
\quad(n=1)\end{array}$ & $\begin{array}{c}\text { Total } \\
(n=13)\end{array}$ \\
\hline Number of girls & 1 & 5 & 1 & 7 \\
\hline Number of boys & 1 & 5 & 0 & 6 \\
\hline SGA & 1 & 0 & 0 & 1 \\
\hline LBW $(1,500-2,500 \mathrm{~g})$ & 0 & 10 & 1 & 11 \\
\hline $\operatorname{VLBW}(1,000-1,500 \mathrm{~g})$ & 2 & 0 & 0 & 2 \\
\hline ELBW $(-1,000 \mathrm{~g})$ & 0 & 0 & 0 & 0 \\
\hline Anglophone & 1 & 3 & 1 & 5 \\
\hline Anglo-dominant & 1 & 2 & 0 & 3 \\
\hline Franco-dominant & 0 & 5 & 0 & 5 \\
\hline Brief $10^{1}$ & $90.0(4.20)$ & $111.70(14.20)$ & 93 & 13 \\
\hline
\end{tabular}

$S G A=$ small for gestational age; $L B W=$ low birth weight, $V L B W=$ very low birth weight, ELBW = extremely low birth weight.

${ }^{1}$ When there was more than 1 participant, the mean and standard deviation of the group are presented. 
pressive language over and above variance accounted for by early language, age and parent education [55].

The assessment procedure followed that of AUTHOR et al., 2014. All tasks were administered to bilingual children. For Anglophone children, only the English-language tasks were administered. Children enrolled in either junior or senior kindergarten and $>6$ years of age were administered preschool versions of the standardized tools. For all tools, examiners followed the procedures found in the examiner's manual. The children were assessed by a registered speech-language pathologist or a bilingual research assistant in a quiet room either at their home or in their school.

\section{Measures of linguistic knowledge:}

1. The Peabody Picture Vocabulary Test-4 (PPVT-4) was used with all children [56].

2. The Échelle de vocabulaire en images Peabody (ÉVIP) was used with all bilingual children [57]. This tool was adapted from its original English form (PPVT) for French Canadians and standardized with this group.

3. The Expressive Vocabulary subtest (EV) of the Clinical Evaluation of Language Fundamentals-Preschool 2 (CELF-P2) was used with all children $<6$ years old [58].

\section{Measures of linguistic processing:}

1. The following subtests of the CELF-P2 were used with all children $<6$ years old: Concepts \& Following Directions (C\&D), Recalling Sentences (RS) [58].

2. The following subtests of the CELF-5 were used with all children $>6$ years old: Following Directions (FD), Recalling Sentences (RS) [59].

3. The following subtests of the Évaluation clinique des notions langagières fondamentales - version pour francophones du Canada (CELF CDN-F) were used with all bilingual children $>4$ years old: Concepts et exécution des directives (C\&D) (Concepts \& Following Directions), Répétition de phrases (RP) (Recalling Sentences) [60].

4. The Rapid Automatic Naming (RAN) subtest of the CELF- 4 was used with all children $>6$ years old to measure processing speed and phonological retrieval [61]. This task evaluates a child's ability to process and store repeated visual stimuli in working memory and to recall the visual stimuli automatically, precisely, rapidly and fluidly, as well as measure phonological retrieval. Scores for accuracy in naming (RAN-err) and processing time (RAN-sec) were calculated.
5. The Dénomination automatique rapide (Rapid Automatic Naming) (DAR) subtest of the CELF-CDN-F was used with bilingual children $>4$ years old to measure processing speed and phonological retrieval [60]. This task evaluates a child's ability to process and store repeated visual stimuli in working memory and to recall the visual stimuli automatically, precisely, rapidly and fluidly, as well as measure phonological retrieval. Scores for accuracy in naming (DAR-err) and processing time (DARsec) were calculated.

\section{Measures of working memory:}

1. The Répétition des non-mots task (Non-word Repetition Task) (RNM) developed by Courcy for Franco-Quebecers (2000) was used with all bilingual children [62]. The abbreviated list includes 40 words having one to five syllables and is a measure of phonological memory. The percentage of correct phonemes produced was calculated [40].

2. The Children's Test of Non-Word Repetition (NWR) was used with all children. The percentage of correct phonemes produced was calculated [63].

3. The Répétition des nombres (Number Repetition) $(R N)$ subtest of the CELF CDN-F was used with all bilingual children $>4$ years old [60].

4. The Number Repetition (NR) subtest of the CELF-4 was used with all children $>6$ years old [61].

Interrater validity was calculated for all tasks requiring transcriptions. An independent judge listened to all recorded samples. When there was disagreement, a third judge conducted an inspection of the transcriptions to arrive at a single verified response. The interrater validity was $80 \%$.

PPVT-4 and ÉVIP scores are reported in raw scores and standard scores, according to the published norms; for these tests, a standard score between 85 and 115 is considered within the average range $[56,57]$. The CELF-P2, CELF-4, CELF-5 and CELF-CDN-F subtests scores are presented in raw scores and standard scores; a standard score between 7 and 13 is considered within the average range [58-61]. In the non-word repetition tasks (NWR/RNM), the number of phonemes that were correctly repeated and the total number of phonemes to be produced were used in order to calculate a percentage of accuracy. For the French rapid automatic naming task $(D A R)$, the number of errors and the time required to complete the task was calculated in order to determine the participants' scores; a standard score between 7 and 13 is 
Table 2. French language test scores for French-dominant and English-dominant children.

\begin{tabular}{|c|c|c|c|c|c|c|c|c|}
\hline Participants & 03 & 04 & 05 & 06 & 07 & 08 & 09 & 13 \\
\hline Age & $5 ; 9$ & $5 ; 9$ & $6 ; 4$ & $7 ; 7$ & $7 ; 7$ & $7 ; 7$ & $8 ; 7$ & $9 ; 2$ \\
\hline Linguistic dominance & FD & $\mathrm{FD}$ & ED & $\mathrm{FD}$ & FD & FD & ED & ED \\
\hline Prematurity & Very & Very & Very & Very & Very & Very & Very & Ext. \\
\hline Birth weight & LBW & LBW & LBW & LBW & LBW & LBW & LBW & ELBW \\
\hline Maternal education & Master's level & Master's level & College & Bachelor's level & Bachelor's level & College & College & College \\
\hline EVIP-raw & 82 & 88 & 45 & 109 & 89 & 82 & 93 & 91 \\
\hline EVIP-SS & 124 & 131 & $84^{*}$ & 128 & 109 & 103 & 103 & 95 \\
\hline RNM & $78.6 \%$ & $87.1 \%$ & $56 \%^{\lambda}$ & $88.2 \%$ & $94.6 \%$ & $83.2 \%$ & $86.1 \%$ & $82.9 \%$ \\
\hline$D A R$-err & 0 & 0 & 0 & 0 & 0 & 0 & 1 & 2 \\
\hline$D A R$-sec & 151.18 & 215.05 & 477.58 & 90 & 120 & 146.28 & 196.58 & 173 \\
\hline DAR-SS & $6^{*}$ & $6^{*}$ & $3 * * *$ & 10 & $7^{*}$ & $6^{*}$ & $5^{* *}$ & $4^{* *}$ \\
\hline CELF-CDN-F-C\&D raw & 43 & 43 & 25 & 52 & 49 & 41 & 47 & 39 \\
\hline CELF-CND-F C\&DSS & 15 & 15 & 8 & 17 & 15 & 10 & 11 & 8 \\
\hline CELF-CND-F- $R N$ raw & 10 & 10 & 5 & 11 & 13 & 11 & 11 & 7 \\
\hline CELF-CND-F RNSS & 12 & 12 & $6^{*}$ & 11 & 13 & 11 & 10 & $5^{* *}$ \\
\hline CELF-CND-F RP raw & 38 & 47 & 27 & 39 & 51 & 42 & 43 & 62 \\
\hline CELF-CND-F-RPSS & 11 & 13 & $7^{*}$ & 9 & 12 & 9 & 8 & 14 \\
\hline
\end{tabular}

$S S=$ standard score.

${ }^{\lambda}=$ raw score is between -1 and -1.5 SD from the mean (AUTHOR et al., 2014).

${ }^{*}=$ SS is between -1 et -1.5 SD from the mean; ${ }^{* *}=S S$ is between -1.5 et -2 SD from the mean; ${ }^{* *}=S S$ is 2 SD or more from the mean.

considered within the average range. For the English rapid automatic naming task (RAN), the number of errors and the time required to complete the task yielded one of three results: normal, slower than normal, out of the norm. There were 36 items per task for children 6 years or older and 24 elements per task for children under 6 years.

\section{RESULTS}

The scores for the French language tasks can be found in Table 2. The scores for the English-language tasks can be found in Table 3.

\section{Measure of linguistic knowledge}

Two measures of linguistic knowledge were collected: receptive and expressive vocabulary. In all participants $<6$ years of age, receptive vocabulary scores were within the average range, as measured by the PPVT-4. In this same group, expressive vocabulary scores (EV) were below the average range for two (50\%) bilingual participants. These participants were FD, born very premature and came from homes with a high level of maternal education. In this case, it is important to note that the subtest was administered in the non-dominant language.
In all participants $>6$ years of age, receptive vocabulary scores were within the average range in both languages. One bilingual participant (ED, very premature) received a receptive vocabulary score (EVIP) in French, the non-dominant language, between -1 and -1.5 SD from the mean.

Overall, all receptive vocabulary scores in the participants' dominant language were in the high average or above average range, demonstrating that this measure of linguistic knowledge was a relative strength in this sample.

\section{Measures of linguistic processing}

Comprehension of directives (C\&D) was the first measure of linguistic processing. Two participants received a score below the average range on this task in English. Participant 7 was born very prematurely and is FD, therefore completed this task in his non-dominant language. Participant 12 is ENG, was born extremely premature and with ELBW.

Overall, performance on this task was generally judged to be good, as most participants (85\%) scored within the average range, regardless of language dominance, degree of prematurity or birth weight category.

RAN was the second measure of linguistic processing. Please note that four participants $>6$ years of age did not 
Table 3. English language tests scores

\begin{tabular}{|c|c|c|c|c|c|c|c|c|c|c|c|c|c|}
\hline Participants & 01 & 02 & 03 & 04 & 05 & 06 & 07 & 08 & 09 & 10 & 11 & 12 & 13 \\
\hline Age & $5 ; 7$ & $5 ; 7$ & $5 ; 9$ & $5 ; 9$ & $6 ; 4$ & $7 ; 7$ & $7 ; 7$ & $7 ; 7$ & $8 ; 7$ & $8 ; 11$ & $6 ; 0$ & $7 ; 3$ & $9 ; 2$ \\
\hline Linguistic dominance & ENG & ENG & FD & $\mathrm{FD}$ & ED & FD & FD & $\mathrm{FD}$ & ED & ENG & ENG & ENG & ED \\
\hline Prematurity & Very & Very & Very & Very & Very & Very & Very & Very & Very & Very & Mod. & Ext. & Ext. \\
\hline Birth Weight & LBW & LBW & LBW & LBW & LBW & LBW & LBW & LBW & LBW & LBW & $\begin{array}{c}\text { LBW/ } \\
\text { SGA }\end{array}$ & ELBW & ELBW \\
\hline Maternal education & $\mathrm{BA}$ & $\mathrm{BA}$ & MA & MA & College & $\mathrm{BA}$ & $\mathrm{BA}$ & College & College & $\mathrm{N} / \mathrm{A}$ & $\mathrm{N} / \mathrm{A}$ & Sec. & College \\
\hline PPVT-raw & 87 & 114 & 112 & 90 & 120 & 123 & 106 & 113 & 148 & 154 & 102 & 141 & 159 \\
\hline PPVT-SS & 97 & 114 & 111 & 97 & 113 & 97 & 87 & 92 & 108 & 110 & 101 & 114 & 113 \\
\hline NWR & $88,7 \%$ & $91,2 \%$ & $74,2 \%^{\lambda}$ & $94,9 \%$ & $77,1 \%^{\lambda}$ & $92,9 \%$ & $94,1 \%$ & $85,4 \%$ & $95,2 \%$ & $96,3 \%$ & $92,4 \%$ & $84,7 \%^{\lambda}$ & $97,7 \%$ \\
\hline CELF-P-EV raw & 28 & 28 & 18 & 16 & & & & & & & & & \\
\hline CELF-PEV SS & 9 & 9 & $6^{*}$ & $5^{* *}$ & & & & & & & & & \\
\hline CELF-PC\&D raw & 16 & 19 & 20 & 21 & & & & & & & & & \\
\hline CELF-PC\&D SS & 10 & 12 & 13 & 15 & & & & & & & & & \\
\hline CELF-PRS raw & 24 & 13 & 23 & 20 & & & & & & & & & \\
\hline CELF-PRS SS & 9 & $6^{*}$ & 9 & 8 & & & & & & & & & \\
\hline RAN-err & 0 & 0 & $\mathrm{n} / \mathrm{a}$ & $\mathrm{n} / \mathrm{a}$ & 17 & 0 & 0 & 2 & 0 & 0 & 1 & 1 & 0 \\
\hline RAN-sec & 63 & 73 & $\mathrm{n} / \mathrm{a}$ & $\mathrm{n} / \mathrm{a}$ & 320 & 63 & 124 & 102 & 121,51 & 63 & 132 & 112 & 112 \\
\hline RAN SS & & & & & ON & $\mathrm{N}$ & SN & $\mathrm{N}$ & SN & $\mathrm{N}$ & $\mathrm{N}$ & $\mathrm{N}$ & SN \\
\hline \multicolumn{14}{|l|}{ CELF-5 } \\
\hline FD raw & & & & & 14 & 23 & 11 & 22 & 19 & 26 & 11 & 4 & 22 \\
\hline \multicolumn{14}{|l|}{ CELF-5 } \\
\hline FD SS & & & & & 12 & 14 & $7^{*}$ & 13 & 10 & 14 & 10 & $3^{* * *}$ & 12 \\
\hline \multicolumn{14}{|l|}{ CELF-5 } \\
\hline RS raw & & & & & 11 & 9 & 0 & 16 & 20 & 51 & 28 & 12 & 14 \\
\hline \multicolumn{14}{|l|}{ CELF-5 } \\
\hline RS SS & & & & & $6^{*}$ & $3^{* * *}$ & $1^{* * *}$ & $5^{* *}$ & $5^{* *}$ & 12 & 8 & $5^{* *}$ & $4^{* *}$ \\
\hline \multicolumn{14}{|l|}{ CELF-4 } \\
\hline NR raw & & & & & 5 & 11 & 12 & 10 & 10 & 20 & 6 & 12 & 8 \\
\hline \multicolumn{14}{|l|}{ CELF-4 } \\
\hline NR SS & & & & & $5^{* *}$ & 10 & 11 & 8 & $7^{*}$ & 16 & $7^{*}$ & 11 & $5^{* *}$ \\
\hline
\end{tabular}

$\mathrm{BA}=$ bachelor's degree; $\mathrm{MA}=$ master's degree; College=college degree; $\mathrm{Sec} .=$ high school diploma; $\mathrm{N}=$ norm; $\mathrm{SN}=$ slower than the norm; $\mathrm{ON}=$ out of the norm.

${ }^{\lambda}={ }^{*}{ }^{*}=$

complete this task in English due to age limits on the CELF-4. On this task, four bilingual participants fell below the average range in both languages, while three bilingual participants (FD) were below average in French, their dominant language. Overall, participants who struggled with this task (54\%) had varying degrees of prematurity, birth weight and levels of maternal education.

The final measure of linguistic processing was sentence recall (RS/RP). In English, one of four (25\%) Anglophone participants $<6$ years and seven out of nine $(77.8 \%)$ bilingual par- ticipants $>6$ years of age obtained below average scores on this task. In three of these cases, the task was completed in the child's non-dominant language. In French, one (ED, born very prematurely, LBW) of eight participants (12.5\%) scored below the average range. In total, nine of thirteen participants (69.2\%) received scores below the average range for their age in at least one language on this task. Performance on this task was consequently judged to be weak; this was the case regardless of language dominance, birth weight or degree of prematurity. 


\section{Working memory}

Two measures of working memory were collected in the context of this study: non-word repetition (NWR, $R N M$ ) and number repetition $(\mathrm{NR} / R N)$. In the NWR task, the participants were required to repeat a list of non-words that followed the rules of either French or English orthography. Using the number of phonemes that were correctly repeated and the total number of phonemes to be produced, a percentage of accuracy was calculated. Generally, a percentage of accuracy beyond 85 to $90 \%$ is expected in English 5-year-old children with typical development. [64] According to the regional data provided by AUTHOR et al. (2014), bilingual children aged four to six years completed this task with 63 to $71 \%$ accuracy, while children aged eight to nine years completed this task with 70 to $90 \%$ accuracy [35].

Using these norms, we determined that one participant out of four $(25 \%)<6$ years of age received an accuracy score below the average range in English; this participant was FD and therefore completed this task in his non-dominant language. In participants $>6$ years of age, one participant (ENG, born extremely prematurely, ELBW) received a score below the average range in English and one participant (ED, born very premature, LBW) received a score below the average range in both languages. Overall, performance on this task was judged to be good as $84.6 \%$ of the sample performed within the average range in their dominant language.

Finally, on the number repetition (NR/RN) task, two ANG participants received below average scores in English, their dominant language, and two bilingual participants fell below the average range in both languages. Consequently, almost half the sample (44\%) were found to struggle with this task.

\section{PLI diagnosis}

A cut-off score for all sub-tests was required in order to accurately identify children with a primary language disorder (PLI). Presently, there is no agreement on a valid measurement. For this reason, the cut-off point chosen was that of 1 to 1.25 standard deviation (SD) below the mean on at least two subtests in the child's dominant language. This cut-off was based on a study conducted by Elin Thordardorttir et al., (2010), who demonstrated that the ideal cut-off point for French language tests is between the average and -1SD [65]. For English language tests, two or more scores below -1.25 SD has been shown to be ideal for the diagnosis of Specific Language Impairment (SLI) [66]. Using these cut-off scores, one ENG (\#12) and three ED $(\# 5,9,13)$ were identified as having a
PLI. Overall, four of thirteen participants (7.7\%) were identified as having a PLI. Of these, two were born very prematurely and with LBW (20\%) and two were born extremely prematurely and with ELBW (100\%).

\section{Interpretation}

Using a formal evaluation battery comprised of French and English language tests, this study examined the linguistic knowledge, linguistic processing and working memory of premature children having average non-verbal language skills. In this sample, two participants ( $15 \%$ of the sample) were born extremely premature and with ELBW, one moderately premature and SGA $(7.7 \%)$ and ten very premature, with LBW (76.9\%). Participants were also divided into three linguistic groups: monolingual children speaking English (ENG) $(n=5$, $\mathrm{X}=6.6$ years; $\mathrm{SD}=1.1$ ), bilingual children whose dominant language was French $(\mathrm{FD})(\mathrm{n}=5, \mathrm{X}=9.3$ years; $\mathrm{SD}=0.99)$ and bilingual children whose dominant language was English (ED) $(\mathrm{n}=3, \mathrm{X}=8.1$ years; $\mathrm{SD}=1.5)$. Due to the small sample size, results will be interpreted informally.

Overall, performance on measures of linguistic knowledge was within the average for all participants, in their dominant language. In two cases, below average scores were found in the participants' non-dominant language. Overall, high average or above average scores were noted. Consequently, receptive and expressive vocabulary, measures of linguistic knowledge, were considered a strength in this sample. This is consistent with some literature demonstrating that in Quebec and Ontario monolinguals, vocabulary skills are often underestimated by the EVIP, a French translation of the PPVT. The preliminary data provided here demonstrates that this might also be the case in bilingual children $[35,67,68]$.

Participants were found to have difficulty with two of three tasks measuring linguistic processing. On the Rapid Automatic Naming subtest, $54 \%$ of participants struggled to complete this task according to test standards. Of these, one participant was born extremely premature and with ELBW (50\% of the sample) and six very prematurely, with LBW (60\%). On the Recalling Sentences subtest, $69 \%$ of participants performed below the average range, of which two were born extremely prematurely ( $100 \%$ of the sample) and six very prematurely $(60 \%)$. In both cases, below average scores were noted in the child's dominant language or in both languages.

In measures of working memory, one of two measures was difficult: Number Repetition. On this task, $38 \%$ of the scores were substandard. Of the participants who experienced diffi- 
culty, one was born extremely premature with ELBW, two very premature with $\mathrm{LBW}$ and one moderately premature who was SGA.

Finally, using the cut-off scores determined by Elin Thordardorttir et al. (2010) for bilinguals and Tomblin, Records \& Zhang (1996) for monolinguals, one ENG and three ED, or $7.7 \%$ of the sample, were identified as having a PLI $[65,66]$. Of these, two participants (100\%) were born extremely premature with ELBW and two very premature with LBW (20\%). Given the small number of participants, we are unable to determine if bilingual children are at higher risk of PLI given their minority linguistic status. However, we can report that in our bilingual participants, $80 \%$ of FD and $100 \%$ of ED had at least one substandard score in their dominant language. Interestingly, this was only the case in $40 \%$ of monolinguals.

We then sought to review all the participants' performance in the AUTHOR (2013) study [41]. At 24 months, we concluded that only two participants, \#8 and \#9, were found to have delays in their linguistic development and were referred to speech-language pathology services. In the present study, participant \#8 received only one substandard score (RS), completed in the non-dominant language, and therefore demonstrated catch-up growth. Participants \#5, 12 and 13 were not found to have delays at 24 months; consequently, these developed at a later age.

In the review of the literature, we reported that in preterm children, communication and language are the most commonly affected domains from the preschool years into adolescence [17]. Overall, our results support the fact that, in samples of preterm children with broader gestational ages, simple language functions are in the norm, but more complex language skills are affected [16]. In this study, simple language functions (measures of expressive and receptive vocabulary) were labelled as linguistic knowledge, while complex language measures (comprehension of meaning and linguistic structure, attention to form and details) were labelled as functions of linguistic processing. All measures of simple language function, or linguistic knowledge, were within the average range, regardless of gestational age. Conversely, $54 \%$ of participants from all gestational age and birth weight categories received substandard scores on at least one complex language function measure, or linguistic processing, in their dominant language. Finally, $38 \%$ of the sample struggled with tasks involving working memory, again regardless of gestational age and birth weight categories. As van Noort-van der Spek, Franken, \& Weisglas-Kuperus reported, this was the case even in the absence of major disabilities and independent of socioeconomic status [16]. Given that three of the four participants identified as having a PLI were not found to have language delays during the preschool period in the AUTHOR (2013) study, our results also support the fact that difficulties can become apparent with age [15].

Regarding gestational age categories, Kern and Gayraud (2007), who studied the lexical and grammatical development in a group of Francophone preterm infants, demonstrated that moderately premature infants did not differ significantly from that of term infants [12]. However, children born extremely and very premature repeatedly had scores that were significantly lower than those of their peers born at term. Our results were similar: in participants with 2 or more substandard scores, all were born either very or extremely prematurely. In this sample, only one participant was born moderately preterm; a higher number of participants would be necessary in order to determine is these infants are at increased risk for delays later on.

Finally, given that all of our participants demonstrated average non-verbal intelligence and that some participants were diagnosed with PLI, our results do not support those of other authors reporting that language deficits observed in pretermborn children are more likely a result of general cognitive difficulties [21,22].

\section{Limits}

The sample size and the small number of participants in each subcategory are the greatest limitations of the study. However, small studies do have an important role to play in data knowledge translation. As stated during the literature review, the landscape of neonatal follow up is changing, with minor morbidities having a higher prevalence among survivors, even those born moderately or late preterm. The traditional adverse outcomes of the preterm infant are widely published: cerebral palsy, vision/hearing, and cognitive impairment. However, very little is known regarding these minor morbidities, even though a higher prevalence is reported in the literature. Small- $n$ research designs provide information directly relevant to the individual participants being studied. [69] Also, this information could be used to plan larger confirmatory studies [69]. Although the results presented here need to be interpreted with caution, they provide evidence for the longterm follow up on children born prematurely, as well as the monitoring and ongoing assessment of tasks involving information processing and working memory. Data taken from 
this study could be used by health care professionals or early intervention programs in order to better understand the developmental domains that can be at risk in premature infants and monitor them accordingly.

Another limitation is the lack of a control group. A comparison using a local control group would have allowed us to better determine the linguistic knowledge, linguistic processing and working memory skills that are vulnerable to delays. As reported, given the complexity of variables being studied however, it was not possible to find control subjects that matched the age, nonverbal IQ, linguistic status and maternal education of our participants.

Finally, in this sample, the average maternal education was judged to be high. It is possible that this acted as a protective factor in the development of the sample's linguistic skills. With a larger sample and control group, results might differ.

\section{CONCLUSIONS}

This study was designed to further our understanding of the language trajectory of premature infants. We examined linguistic knowledge, linguistic processing and working memory in monolingual and bilingual school-aged children born prematurely, creating preliminary data on linguistic outcomes in this population. In this sample, two participants were born extremely premature, one moderately premature and ten very premature. Participants were also divided into three linguistic groups: monolingual children speaking English, bilingual children whose dominant language was French and bilingual children whose dominant language was English.

First, our results suggest than when assessing children born prematurely, it is important to include measures of linguistic processing and working memory, as most participants struggled with these types of tasks in their dominant language, or in both. This information is even more pertinent given that all participants in our sample had nonverbal skills within normal limits, were born with higher gestational ages (very prematurely) and came from a home with a high level of maternal education (e.g. college or greater).

Our results corroborate those of other researchers who have shown that in premature children, difficulties in working memory, attention and executive functions occur [70,71]. It is possible that the difficulties experienced in our cohort may be based on weaknesses of this order and present themselves regardless of linguistic dominance. Future researchers should evaluate working memory, attention and executive functions in more detail in order to determine their influence on language development.

Second, we reported that since many children live in multilingual and multicultural environments, it is imperative to consider linguistic input and language dominance when preparing for an evaluation. In Official Minority Language Communities (OMLC), the lack of standardized assessment tools and regional norms makes this process difficult. The information presented in the context of this project provide other researchers preliminary data on the performance of bilingual children born prematurely and living in a minority context, information that is presently lacking in the literature. In this sample, bilingual children received more substandard scores in their dominant language than monolinguals. Although more children identified as having a PLI in this sample were bilingual, a larger sample with a control group would be required in order to determine if minority language children are at increased risk of PLI.

Our findings have several implications. First, it goes without saying that the close surveillance of the premature child is essential. Our results suggest that, even if simple language skills, or linguistic knowledge, are within normal limits, and indepth assessment should take into account linguistic processing and working memory as these were found to be a weakness in this sample. It is unknown if these weaknesses could lead to more significant difficulties and impact academic success long term. Also, long-term follow-up is necessary. In some participants, delays were not noted during the preschool difficulties and developed at a later stage. Ongoing monitoring into early school grades is recommended.

Further, the implication of minority and majority linguistic status on language development needs to be further investigated in order to determine if minority language children are at increased risk of delays. Finally, the identification of biological and sociodemographic risk factors associated with delays in all premature children is paramount. Weaknesses were noted in participants with a variety of gestational ages and birth weight categories.

\section{REFERENCES}

1. Canadian Institute for Health Information. Too early, too small: a profile of small babies across Canada. Ottawa ON, CIHI; c2009.

2. Blencowe H, Cousens S, Oestergaard MZ. National, regional, and worldwide estimates of preterm birth rates in the year 2012 with time trends since 1990 for selected countries: a systematic analysis and implications. Lancet. 2012;379:2162-2172. 
3. World Health Organization. Women and health: today's evidence, tomorrow's agenda. Geneva: Switzerland; 2009.

4. Gardner S, Goldson, E. Handbook of neonatal intensive care (6th ed.). St. Louis, Missouri: Mosby Elsevier; 2006.

5. Church P, Luther M, Asztalos E. The perfect storm: the high prevalence low severity outcomes of the Preterm Survivors. Curr Pediatr Rev. 2012;8(1):1-10.

6. Alyward GP. Neurodevelopmental outcomes of infants born prematurely. J Beh Ped. 2005;26:427-440.

7. Chyi L, Lee HC, Hintz SR, Gould JB, Sutcliffe TL. School outcomes of late preterm infants: special needs and challenges for infants born at 32 to 36 weeks' gestation. J Pediatr. 2008;153:25-31.

8. Talge NM, Holzman C, Wang J, Lucia V, Gardiner J, Breslau N. Late-term birth and its association with cognitive and socioemotional outcomes at 6 years of age. Pediatr. 2010;126(6):1124-1131.

9. Vergara E, Bigsby R. Developmental and therapeutic interventions in the NICU. Maryland: Brookes Publishing Co.; 2004. p. 352.

10. Hoekstra RE, Ferrara TB, Couser RJ, Payne NR, Connett JE. Survival and long-term neurodevelopmental outcome of extremely premature infants born at 23-26 weeks' gestational age at a tertiary centre. J Pediatr. 2004;113:e1.

11. Bhutta AT, Cleves MA, Casey PA. Cognitive and behavioral outcomes of school-aged children who were born preterm: A metaanalysis. JAMA. 2002:728-737.

12. Kern S, Gayraud F. Influence of preterm birth on early lexical and grammatical acquisitions in French. First Lang. 2007;27(2):159173.

13. Hack M, Fanaroff A. Outcomes of children of extremely low birthweight and gestational age in the 1990s. Semi Neonatal. 2000: 89106.

14. Briscoe J, Gathercole S, Marlow N. Short term memory and language outcomes after extreme prematurity at birth. J Speech Lang Hear R. 1998;41:654-666.

15. Salt A, Redshaw M. Neurodevelopmental follow-up after preterm birth: follow up after two years. Early Hum Dev. 2006;82:185-197.

16. van Noort-van der Spek I, Franken MC, Weisglas-Kuperus N. Language Functions in Preterm-Born Children: A Systematic Review and Meta-analysis. J Pediatr. 2012;129(4):745-54. doi: 10.1542/ peds.2011-1728

17. Sansavini A, Pentimonti J, Justice L, Guarini A, Savini S, Alessandroni R, Faldella G. Language, motor and cognitive development of extremely preterm children: Modeling individual growth trajectories over the first three years of life. J Commun Dis. 2014;49:5568.

18. The Scottish Low Birth Weight Group. Scottish low birth weight study: II. Language attainment, cognitive status and behavioural problems. Arch Dis Child. 1992;67:682-686.

19. Briscoe J, Gathercole SE, Marlow N. Short-term memory and language outcomes after extreme prematurity at birth. J Speech Lang Hear Res. 1998;41:654-664.

20. Wolke D, Samara M, Bracewell M, Marlow N. Specific Language Difficulties and School Achievement in Children Born at 25 Weeks of Gestation or Less. J Pediatr. 2007;152(2):256-262.e1.

21. Wolke D, Meyer R. Cognitive status, language attainment, and pre-reading skills of 6-year-old very preterm children and their peers: the Bavarian Longitudinal Study. Dev Med \& Child Neurol. 1999;41(2):94-109.

22. Barre N, Morgan A, Doyle LW, Anderson PJ. Language abilities in children who were born very preterm and/or very low birth weight: a meta-analysis. J Pediatr. 2011 158(5):766. e1-774.e1

23. Thordardottir E, Kehayia E, Lessard N, Sutton A, Trudeau N. Typical performance on tests of language knowledge and language processing of French-speaking 5-year-olds. Can J Speech Lang Pathol Audiol. 2010;34(1):5-16.

24. Maas W. Early detection of speech and language delays in the Netherlands. The case for integrating primary and secondary prevention. Child Care Health Dev. 2000;26(2):150-162.

25. Genesee F. What do we know about bilingual education for majority-language students. In The handbook of bilingualism. Malden, MA: Blackwell Publishing; 2004. p. 869.

26. Kohnert K. Bilinguals with primary language impairment. In K. De Bot et R. Schrauf (Eds), Language development over the lifespan. Mahwah, NJ: Erlbaum; 2010. p. 312.

27. Westman M, Korkman M, Mickos A, Byring R. Language profiles of monolingual and bilingual Finnish preschool children at risk for language impairment. Int J Lang Comm Dis. 2008;43(6):699711.

28. Gathercole VCM. Bilingualism matters: One size does not fit all. Special section: Language development in multilingual environments. Int J Behav Dev. 2014;38(4):359-66.

29. Hoff, E., Core, C., Place, S., Rumiche, R., Senor, M., Parra, M. (2012). Dual language exposure and early bilingual development. J Child Lang. 2012;39(1):1-27

30. Gathercole VCM, Pérez Tattam R, Stadthagen-Gonzalez H, Thomas E. Bilingual construction of two systems: To interact or not to interact? In E.M. Thomas \& I. Mennen (eds.), Advances in the study of bilingualism. Bristol: Multilingual Matters; 2014. p. 288.

31. Genesee F. Bilingual first language acquisition: Exploring the limits of the language faculty. Annual Rev Appl Ling. 2001;21:153-168.

32. Churchill S. L'enseignement des langues et l'identité civique canadienne face à la pluralité des identités des canadiens : Guide pour l'élaboration des politiques linguistiques éducatives en Europe. Institut d'études pédagogiques de l'Ontario: Université de Toronto. 2003. Available from: http://www.coe.int/t/dg4/linguistic/Source/ ChurchillFR.

33. Office of the French Language Services Commissioner. Les langues officielles et vous. Commissariat aux langues officielles. 2009. Available from: http://www.ocol-clo.gc.ca/html/faq_f. php\#loi.

34. Laflamme S, Bernier C. Vivre dans l'alternance linguistique : Médias, langage et littératie en Ontario français. Sudbury, Ontario. Centre franco-ontarien de ressources en alphabétisation; 1998. p. 127

35. AUTHOR, Elin Thordardottir, Robillard M, Minor-Corriveau M, AUTHOR. Données langagières franco-ontariennes : effets du contexte minoritaire et du bilinguisme. Can J Speech Lang Pathol Audiol. 2014;38(3):304-324.

36. Landry R, Allard R, Deveau K. École et autonomie culturelle: En- 
quête pancanadienne en milieu scolaire francophone minoritaire. Nouvelles Perspectives Canadiennes, 2010. p. 271.

37. AUTHOR, Robillard M. Importance of Assessing Nonlinguistic Cognitive Skills in Bilingual Children with Primary Language Impairment. Int J Asses Inter. 2014;20(2):25-55.

38. Hickey T. Children's language networks in minority language immersion: What goes in may not come out. Lang Educ. 2007;21(1): 46-65.

39. Labrie N. Mondialisation et conditions de viabilité de la langue française en Amérique du Nord. Présence francophone. 2001; 56:55-71.

40. AUTHOR. Les compétences linguistiques et cognitives des enfants bilingues en situation linguistique minoritaire [dissertation]. Sudbury, ON: Laurentian University; 2013.

41. AUTHOR. Prématurité, langue et pronostics neurodéveloppementaux chez les enfants prématurés nord-ontariens. [doctoral dissertation] Sudbury, ON: Laurentian University; 2013.

42. Roid G, Miller L. Leiter international performance scale-revised. Wood Dale, IL: Stoelting. 1997.

43. Bialystok E, Ryan E. Toward a Definition of Metalinguistic Skill. Merrill Palmer Q. 1985;31(3): 229-251.

44. Baddeley AD, Hitch G. Working memory. In GH Bower (ed), The psychology of learning and motivation: Advances in research and theory. New York: Academic Press; 1974. p. 89.

45. Bryant PE, Bradley L, Maclean M, Crossland J. Nursery rhymes, phonological skills and reading. J Child Lang. 1989;16(2):407-428.

46. Diamond A. Executive functions. Annu Rev Psychol, 2013;64:135168.

47. Miyake A, Friedman NP, Emerson MJ, Witzki AH, Howerter A, Wager TD. The unity and diversity of executive functions and their contributions to complex "frontal lobe" tasks: A latent variable analysis. Cog Psychol. 2000; 41:49-100.

48. Archibald L, Gathercole S. The complexities of complex memory span: Storage and processing deficits in specific language impairment. J Mem Lang. 2007;57:177-94.

49. Baird G, Dworzynski K, Slonims V, Simonoff E. Memory impairment in children with language impairment. Dev Med Child Neurol. 2010;52:535-540.

50. Gillam RB, Cowan N, Day LS. Sequential memory in children with and without language impairment. J Speech Hear Res. 1995;38: 393-402.

51. Marton K, Schwartz R. Working memory capacity and language processes in children with specific language impairment. J Speech Lang Hear Res. 2003;46:1138-1153.

52. Gray S. Diagnostic accuracy and test-retest reliability of nonword repetition and digit span tasks administered to preschool children with specific language impairment. J Commun Disord. 2003; 36(2):129-151.

53. Elin Thordardottir, Brandeker M. The effect of bilingual exposure versus language impairment on nonword repetition and sentence imitation scores. J Commun Disord. 2013;46:1-16.

54. Bishop DVM, Snowling MJ, Thompson PA, Greenhaigh T.
CATALISE Consortium. CATALISE: A Multinational and Multidisciplinary Delphi Consensus Study. Identifying Language Impairments in Children. PLoS ONE 2016;11(7):e0158753.

55. Newbury J, Klee T, Stokes SF, Moran C. Interrelationships between working memory, processing speed, and language development in the age range 2-4 years. J Speech Lang Hear Res. 2016;59(5):1 146-158.

56. Dunn LM, Dunn DM (Eds.). Peabody picture vocabulary test (4th ed.). Minneapolis, MN: NCS Pearson, Inc. 2007.

57. Dunn LM, Thériault-Whalen CM, Dunn DM. Échelle de vocabulaire en images Peabody. Adaptation française du Peabody Picture Vocabulary Test-Revised. Toronto, Ontario: Psycan. 1993.

58. Semel E, Wiig E, Secord W. Clinical evaluation of language fundamentals-preschool (2nd ed). San Antonio, TX: The Psychological Corporation. 2004.

59. Wiig E, Semel E, Secord W. Clinical evaluation of language fundamentals-5. San Antonio, TX: The Psychological Corporation. 2005.

60. Wiig E, Secord W, Semel E, Boulianne L, Labelle M. Évaluation clinique des notions langagières fondamentales : Version pour francophones du Canada. Toronto, Ontario: Pearson Canada Assessment. 2009.

61. Semel E, Wiig E, Secord W. Clinical evaluation of language fundamentals-4. San Antonio, TX: The Psychological Corporation. 2003.

62. Courcy A. Conscience phonologique et apprentissage de la lecture. (Manuscript non publié). Université de Montréal. 2000.

63. Gathercole SE, Willis CS, Baddeley AD, Emslie H. The children's test of non-word repetition: A test of phonological working memory. Memory. 1994;2(2):103-127.

64. Elin Thordardottir, Brandeker M. The effect of bilingual exposure versus language impairment on nonword repetition and sentence imitation scores. J Comm Dis. 2012;1-16.

65. Elin Thordardottir, Keheyia, E, Lessard, N, Sutton A, Trudeau N. Typical performance on tests of language knowledge and language processing of french-speaking 5-year-olds. Can J Speech Lang Pathol Audiol. 2010;34(1):5.

66. Tomblin JB, Records N, Zhang, X. A system for the diagnosis of Specific Language Impairment in Kindergarten children. J Speech Hear Res. 1996;39(6):1284-1294.

67. Elin Thordardottir. The relationship between bilingual exposure and vocabulary development, Int J Biling. 2011;15(4):426-445.

68. Godard L, Labelle M. Utilisation de l'ÉVIP avec une population québécoise. Fréquences. 1995;7:18-21.

69. Graham J, Karmarkar A, Ottenbacher K. Small sample research designs for evidence-based rehabilitation - Issues and methods. Arch Phys Med Rehab. 2012;93(2):suppl.

70. Mulder H, Pitchford N, Marlow N. Processing speed and working memory underlie academic attainment in very preterm children. Arch Dis Child. 2010;95(4): F267-272.

71. Aarnoudse-Moens C, Weisglas-Kuperus N, van Goudoever J, Oosterlaan J. Meta-analysis of neurobehavioral outcomes in very preterm and/or very low birth weight children. Pediatr. 2009; 124(2):717-728. 